International Journal of

Molecular Sciences

ISSN 1422-0067

www.mdpi.com/journal/ijms

Article

\title{
In vitro Antioxidant of a Water-Soluble Polysaccharide from Dendrobium fimhriatum Hook.var.oculatum Hook
}

\author{
Aoxue Luo ${ }^{\dagger}$ and Yijun Fan ${ }^{\dagger} *$ \\ Department of Landscape Plants, Sichuan Agriculture University, Chengdu 611130, China; \\ E-Mail: aoxueluo@hotmail.com \\ $\dagger$ These authors contributed equally to this work. \\ * Author to whom correspondence should be addressed; E-Mail: Yijfan@yahoo.com.cn.
}

Received: 22 April 2011; in revised form: 28 May 2011 / Accepted: 15 June 2011 /

Published: 17 June 2011

\begin{abstract}
A water-soluble crude polysaccharide (DFHP) obtained from the aqueous extracts of the stem of Dendrobium fimhriatum Hook.var.oculatum Hook through hot water extraction followed by ethanol precipitation, was found to have an average molecular weight (Mw) of about $209.3 \mathrm{kDa}$. Monosaccharide analysis revealed that DFHP was composed of mannose, glucose and galactose in a content ratio of $37.52 \%$; $43.16 \%$; $19.32 \%$. The investigation of antioxidant activity in vitro showed that DFHP is a potential antioxidant.
\end{abstract}

Keywords: Dendrobium fimhriatum Hook.var.oculatum Hook; polysaccharide; antioxidant activity; in vitro

\section{Introduction}

Dendrobium fimhriatum Hook.var.oculatum Hook (Chinese name "Ma Bian Shi Hu") is one of the most famous Dendrobium plants in traditional Chinese medicine, it belongs to Orchidaceae, is a precious herbal plant as a therapeutic for nourishing the stomach, promote secretion of saliva, and reduce fever, and it is one of the five species which were specified in the Chinese Phamacopeia (2005). As for Dendrobium species phytochemicals, much research has been carried out on the low molecular compounds, such as bibenzyl [1], phenanthrene [2], and alkaloids [3]. A previous study has proven that the high-molecular-weight compounds such as polysaccharides were major active constituents in 
Dendrobium species [4]. Moreover, most polysaccharides derived from Dendrobium species are relatively nontoxic and do not cause significant side effects, which is a major problem associated with immunomodulatory and antioxidant polysaccharides [5], such as Dendrobium huoshanense [6], Dendrobium nobile Lindl [7], Dendrobium denneanum [8] and Dendrobium chrysotoxum Lindl [9]. However, the polysaccharides from Dendrobium fimhriatum Hook.var.oculatum Hook have not been reported. Therefore, the purpose of the present investigation was to elucidate the isolation and characterization of water-soluble crude polysaccharide from the stems of Dendrobium fimhriatum Hook.var.oculatum Hook, as well as to evaluate its antioxidant activities in vitro.

\section{Results and Discussion}

\subsection{Extraction of Water-Soluble Crude Polysaccharide}

The polysaccharide, named DFHP, was obtained from the stem of Dendrobium fimhriatum Hook.var.oculatum Hook by the method of water-extraction and ethanol-precipitation. The total yield rate of the water-soluble polysaccharide was $18.64 \%$. Because the molecular weight of polysaccharide was an important factor responsible for biological activities, determining the molecular weight was therefore the first step for the study of the polysaccharide. The molecular weight $\left(\mathrm{M}_{\mathrm{w}}\right)$ of DFHP was calculated to be $209.3 \mathrm{kDa}$ based on the calibration curve obtained with standard dextrans.

\subsection{Monosaccharide Composition of DFHP}

Monosaccharide composition of DFHP was analyzed by the trifluoroacetic acid hydrolysis and GC-MS analysis method. The results shown in Figure 1 indicate that D-glucose, D-mannose and D-galactose were the major monosaccharide constituents. The total content of monosaccharide compositions in DFHP was described as follows: mannose: glucose: galactose $=37.52 \%: 43.16 \%: 19.32 \%$.

Figure 1. Monosaccharide compositions of DFHP by GC-MS analysis.

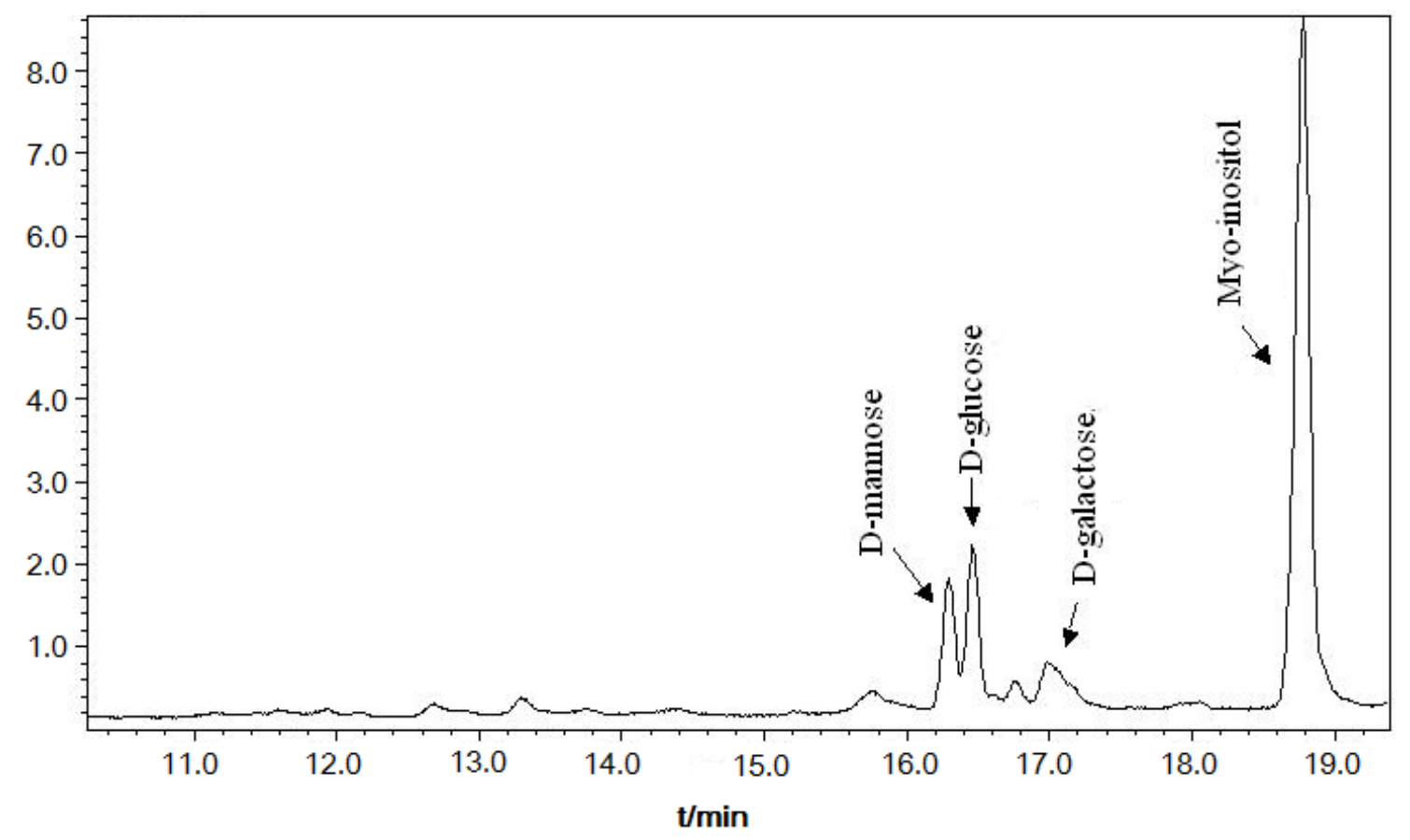




\subsection{Infrared spectra of DFHP}

The FT-IR spectra of the DFHP were presented in Figure.2. The result exhibited a broad stretching intense characteristic peak at around $3422 \mathrm{~cm}^{-1}$ for the hydroxyl group[10], and a weak $\mathrm{C}-\mathrm{H}$ band at around $2929 \mathrm{~cm}^{-1}$ [11]. The band at $1638 \mathrm{~cm}^{-1}$ was due to the bound water [12]. Also it has a specific band in the $1200-1000 \mathrm{~cm}^{-1}$ region, this region was dominated by ring vibrations overlapped with stretching vibrations of $(\mathrm{C}-\mathrm{OH})$ side groups and the $(\mathrm{C}-\mathrm{O}-\mathrm{C})$ glycosidic band vibration [13]. Absorptions at $807 \mathrm{~cm}^{-1}$ were typical for $\alpha$-dominating configuration [14].

Figure 2. FT-IR spectra of the polysaccharide DFHP.

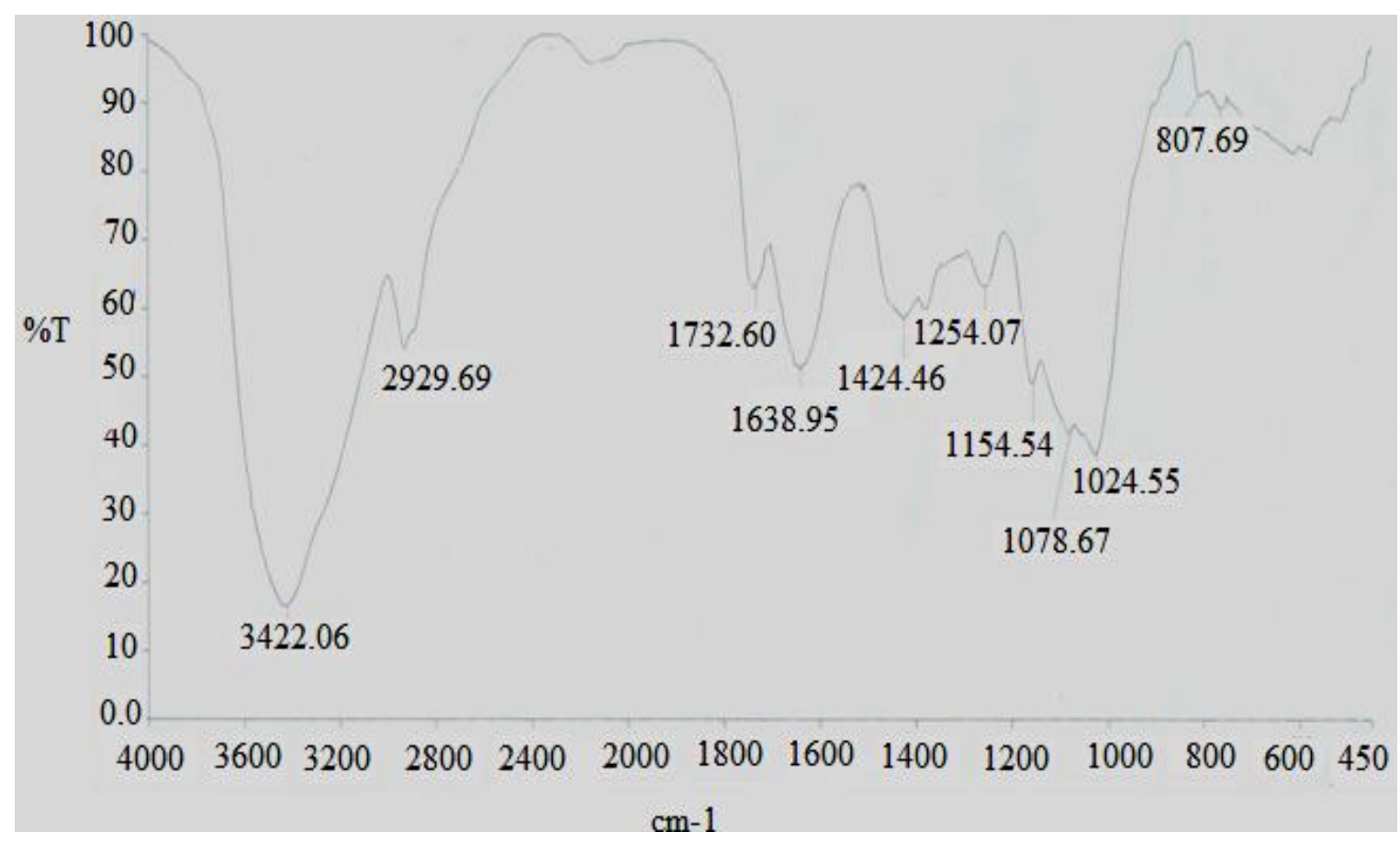

\subsection{NMR Identification of DFHP}

The ${ }^{1} \mathrm{H}-\mathrm{NMR}$ and ${ }^{13} \mathrm{C}-\mathrm{NMR}$ results for DFHP were assigned by comparison with the NMR data reported previously and detailed assignments of all signals are shown in Table 2 [15-18]. Based on previous discussions in the literature, chemical shifts between $\delta 98$ and $103 \mathrm{ppm}$ are a typical feature of the $\mathrm{C}-1$ in $\alpha$-glycosidic linkages (Figure $3 \mathrm{~A}$ ), whereas in the case of $\beta$-glycosidic linkages signals would be expected between $\delta 103$ and $106 \mathrm{ppm}[19,20]$. Thus, the signals were centralized between $\delta 99.63$ and $102.51 \mathrm{ppm}$, indicating $\alpha$ anomeric configuration for all monosaccharide residues of DFHP. The ${ }^{1} \mathrm{H}$ NMR spectrum of DDP showed two anomeric protons at 5.34 and 5.45, which were assigned as $(1 \rightarrow 4)-\alpha$-D-Glcp and $(1 \rightarrow 4)-\alpha$-D-Galp, respectively (Figure $3 B$ ). 
Figure 3. NMR analysis of DFHP. (A) for ${ }^{13} \mathrm{C}-\mathrm{NMR}$ analysis of DFHP, and (B) for ${ }^{1} \mathrm{H}-\mathrm{NMR}$ analysis of DFHP.
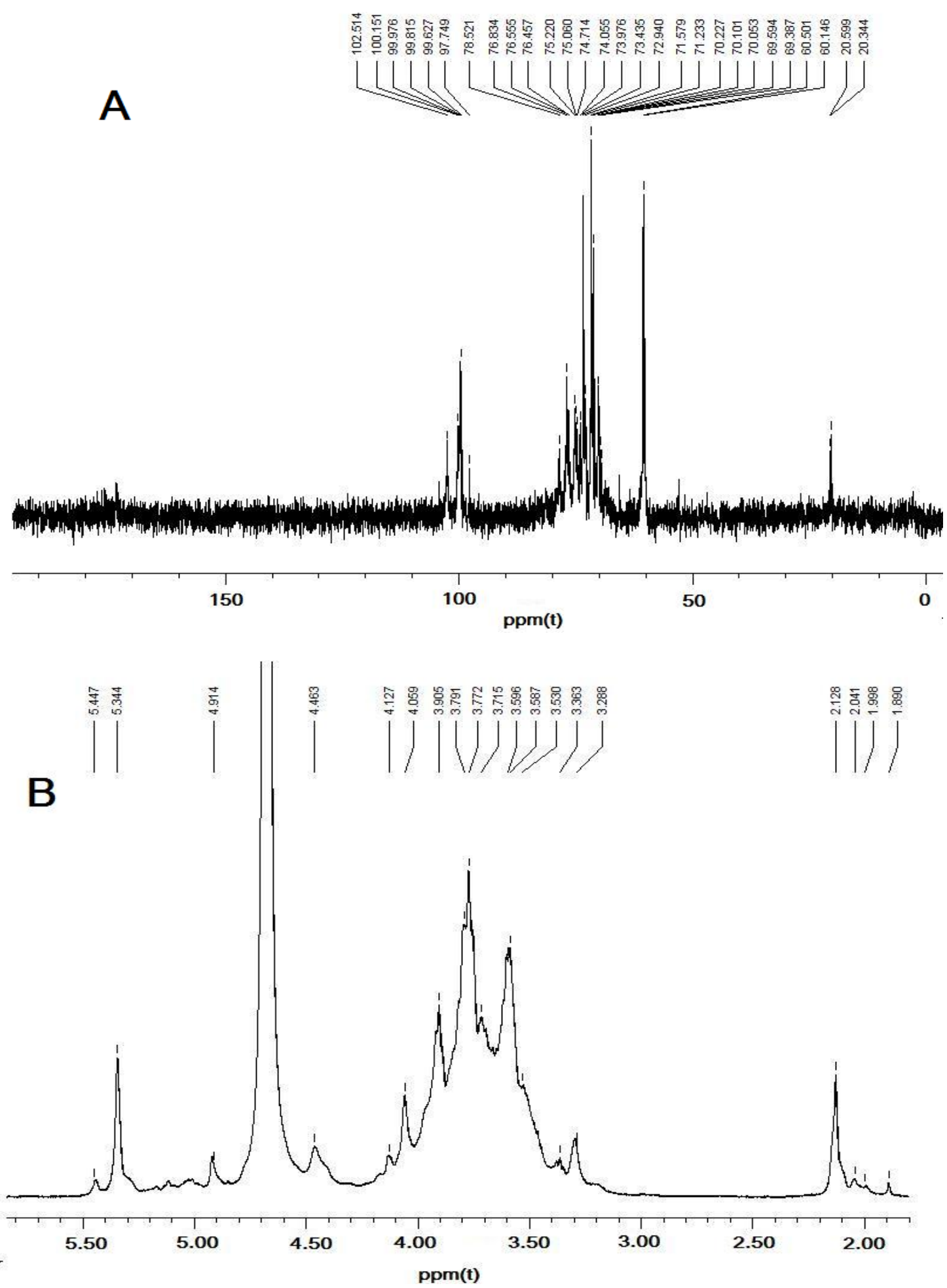

2.5. Antioxidant Activities Analysis

\subsubsection{Effect of Scavenging DPPH Radicals}

The DPPH free radical was a stable radical with a maximum absorption at $517 \mathrm{~nm}$ that can readily undergo scavenging by an antioxidant. So it has been widely accepted as a tool for evaluating the free 
radical scavenging activities of natural compounds. In the test, the scavenging ability of the polysaccharide DFHP on DPPH free radical was examined in the concentration range of 0.001-3.000 mg/mL. The result has been shown in Figure 4. From the figure, the activities of DFHP and $\mathrm{Vc}$ increased in a concentration dependent manner. Vitamin $\mathrm{C}$ exhibited very high radical scavenging activity at high doses $(1.0-3.0 \mathrm{mg} / \mathrm{mL})$. In contrast, the scavenging effect of the polysaccharide DFHP was lower than that of vitamin $\mathrm{C}$ at every dose; even at the high dose of $3.0 \mathrm{mg} / \mathrm{mL}$, the scavenging activity was $46.67 \%$. Therefore, DFHP has insufficient scavenging effect on DPPH radical scavenging.

Figure 4. The scavenging effect of DFHP on DPPH radical. Results are presented as means \pm standard deviations.

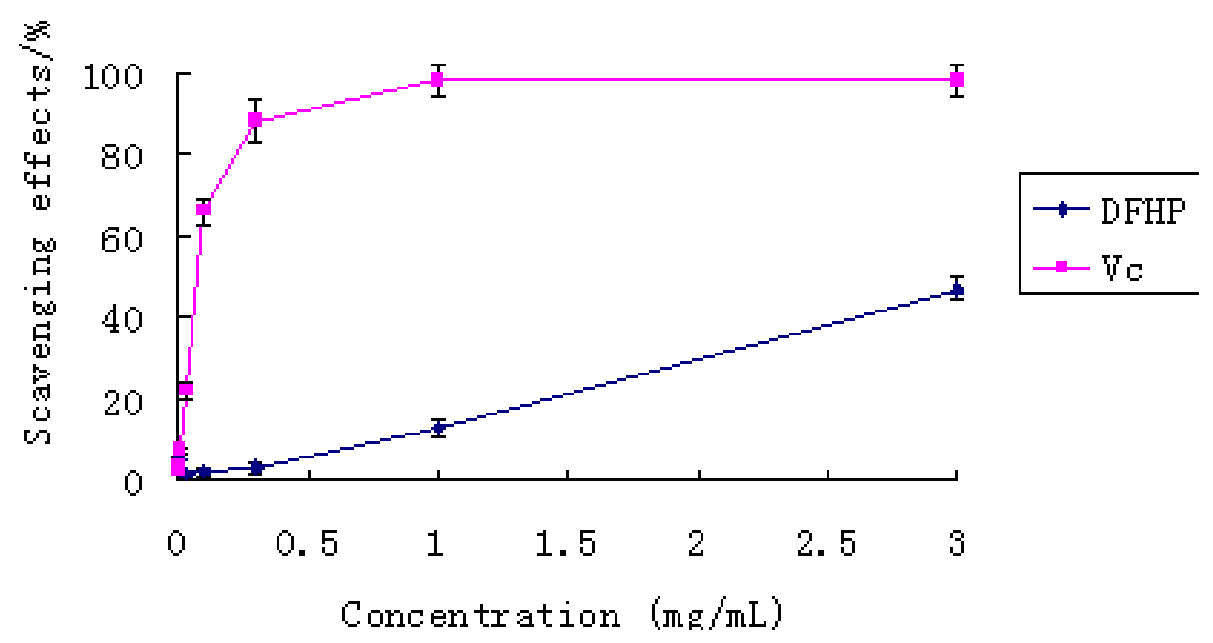

\subsubsection{Scavenging Effects of Polysaccharide on Hydroxyl Radicals}

The scavenging ability of DFHP on hydroxyl free radical was shown in Figure 5. The two samples exhibited obvious hydroxyl radical scavenging activities in a concentration-dependent manner. The polysaccharide was found to have the ability to scavenge hydroxyl radicals at concentrations between 1.0 and $3.0 \mathrm{mg} / \mathrm{mL}$. At $1.0 \mathrm{mg} / \mathrm{mL}$, DFHP revealed an excellent hydroxyl radical scavenging activity (57.22\%), similar to that of vitamin C $(62.22 \%)(P<0.05)$. At the high dose of $3.0 \mathrm{mg} / \mathrm{mL}$, DFHP exhibited very strong activity $(74.78 \%)$, which was close to the reference material vitamin $\mathrm{C}$. These results clearly showed that DFHP has potential hydroxyl radical scavenging antioxidant ability. 
Figure 5. The scavenging effect of DFHP on hydroxyl radical. Results are presented as means \pm standard deviations.

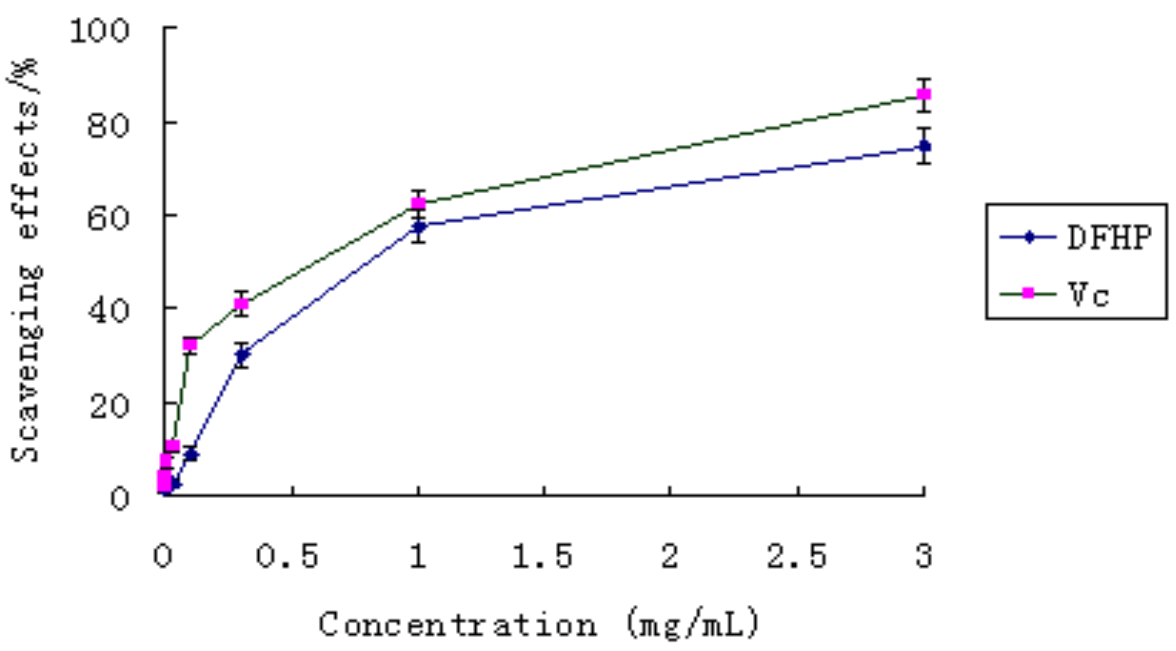

\subsubsection{Scavenging Effects of Polysaccharide on ABTS}

In the scavenging activity on ABTS assay, we employed a specific absorbance $(734 \mathrm{~nm})$ at a wavelength remote from the visible region in a short reaction time, and it can be used in both organic and aqueous solvent systems and can also be an index reflecting the antioxidant activity of the test samples [21]. The scavenging ability of DFHP on ABTS free radical was shown in Figure 6. The scavenging powers of DFHP and Vc correlated well with increasing concentrations. The reference material exhibited an excellent scavenging effect in high doses (from 0.3 to $3.0 \mathrm{mg} / \mathrm{mL}$ ). At the same time, the polysaccharide DFHP also showed high scavenging effect on ABTS. Especially at $3.0 \mathrm{mg} / \mathrm{mL}$, the effect reached $90.05 \%$, which was close to that of vitamin $\mathrm{C}(\mathrm{P}<0.05)$. Therefore, the results indicated that DFHP had strong scavenging power for ABTS radicals and should be explored as novel potential antioxidants.

Figure 6. The scavenging effect of DFHP on ABTS radical. Results are presented as means \pm standard deviations.
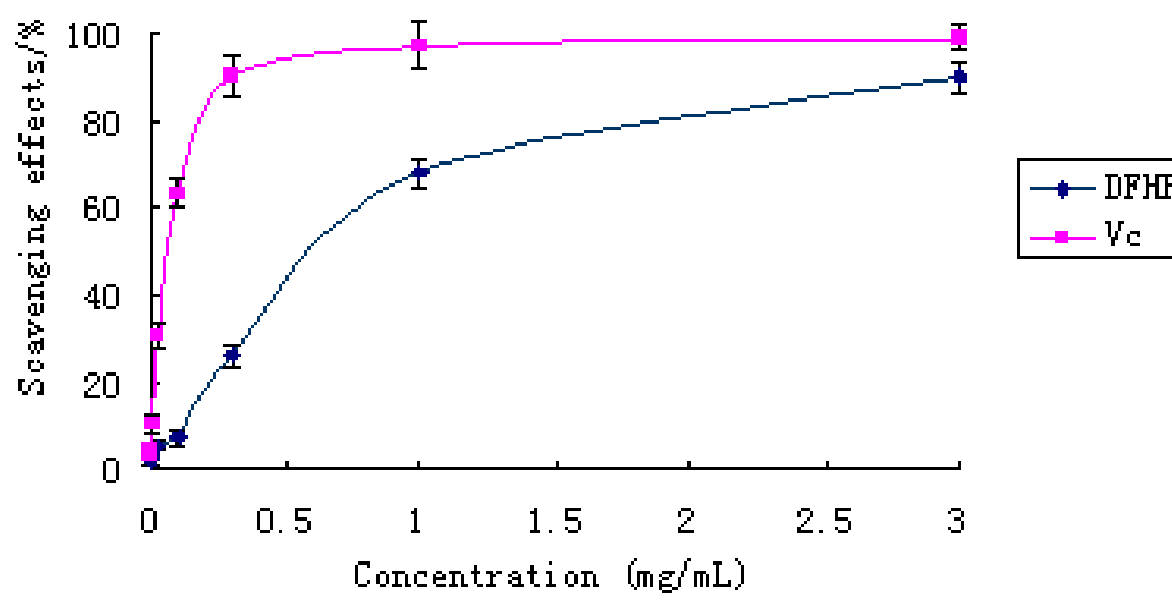


\section{Experimental Section}

\subsection{Materials and Chemicals}

DPPH (1,1-diphenyl-2-picrylhydrazyl) radical and Vitamin C were purchased from Sigma (St. Louis, MO, USA). Dextrans of different molecular weights were purchased from Pharmacia Co. (Uppsala, Sweden). The standard monosaccharides (glucose, mannose, rhamnose, galactose, xylose and arabinose) were purchased from the Chinese Institute for the Control of Pharmaceutical and Biological Products (Beijing, China). ABTS (2,2-azinobis-6-(3-ethylbenzothiazoline sulfonic acid) radical was purchased from Merck Co. (Darmstadt, Germany). Trifluoroacetic acid (TFA), pyridine, methanol, and acetic acid, ethanol, acetic anhydride and all other chemicals and reagents were analytical grade.

\subsection{Preparation of the Polysaccharide from Dendrobium fimhriatum Hook.var.Oculatum Hook}

Preparation of crude polysaccharide was carried out according to the method of Luo et al. [22], with some modifications. The stems of Dendrobium fimhriatum Hook.var.oculatum Hook were thoroughly washed with water, dried at $60{ }^{\circ} \mathrm{C}$, and then powdered with a pulverizer. The powder of Dendrobium fimhriatum Hook.var.oculatum Hook was extracted successively with petroleum ether and ethanol, at first. After filtering, the residue was further extracted with double-distilled water at $100{ }^{\circ} \mathrm{C}$ for $2 \mathrm{~h}$ three times. Then all extracts were combined, concentrated and filtrated. The extract was deproteinized 5 times using the Sevag reagent [23], and the polysaccharide was free of proteins as scan by UV Spectra in $260 \mathrm{~nm}$ and $280 \mathrm{~nm}$. After removal of the Sevag reagent, the extract was precipitated by adding ethanol (4 times the volume of aqueous extract), and the mixture was kept overnight at $4{ }^{\circ} \mathrm{C}$ for the polysaccharides. The precipitate was collected by centrifugation at $4000 \mathrm{rpm}$ for $20 \mathrm{~min}$, washed successively with petroleum ether, acetone and ethanol, the procedure of precipitation was perform iteration, and then dissolved in water and dialyzed against deionized water for $72 \mathrm{~h}$, freeze-drying to yield the crude polysaccharide, which named DFHP.

\subsection{Molecular Weight Determination}

The molecular weights of polysaccharide were determined by Gel Permeation Chromatography (GPC) according to the method of Yamamoto et al. [24], in combination with a Waters HPLC (Waters 515, Massachusetts, USA) equipped with a Ultrahydrogel Linear Column $(300 \times 7.8 \mathrm{~mm})$. The column was eluted with $0.2 \mathrm{M}$ phosphate buffer (PH 7.0) at a flow rate of $0.7 \mathrm{~mL} / \mathrm{min}$ and detected by a Waters 2410 Refractive index detector (RID). The detailed operation conditions were mobile phase: $0.2 \mathrm{M}$ phosphate buffer ( $\mathrm{PH} 7.0$ ); flow rate: $0.7 \mathrm{~mL} / \mathrm{min}$; column temperature: room temperature; injection volume: $20 \mu \mathrm{L}$; running time: $20 \mathrm{~min}$. Dextran standards with different molecular weights $(2500,4600,7100,10,000,21,400,41,100,84,400,133,800,200,000 \mathrm{Da})$ were used for calibration curve. 


\subsection{Analysis of Monosaccharide Compositions}

Identification and quantification of the monosaccharides of DFHP by using GC-MS, at first, $10.0 \mathrm{mg}$ of DFHP hydrolyzed in a sealed glass tube with $2 \mathrm{M}$ TFA $(2 \mathrm{~mL})$ at $100{ }^{\circ} \mathrm{C}$ for $8 \mathrm{~h}$ [25]. Then the hydrolysate was evaporated to dryness and dissolved in $0.5 \mathrm{~mL}$ of pyridine, after $10.0 \mathrm{mg}$ hydroxylamine hydrochloride and $2.0 \mathrm{mg}$ myo-inositol (as internal reference) were added to the solution, it was allowed to react at $90{ }^{\circ} \mathrm{C}$ for $30 \mathrm{~min}$. The tube was cooled to room temperature, and then $0.5 \mathrm{~mL}$ of acetic anhydride was added and mixed thoroughly by vortexing. The tube was sealed and incubated in a water bath shaker set at $90{ }^{\circ} \mathrm{C}$ for $30 \mathrm{~min}$. After cooled, approximately $1.0 \mu \mathrm{L}$ of clear supernatant was loaded onto an Rtx-5SilMS column $(30 \mathrm{~m} \times 0.32 \mathrm{~mm} \times 0.25 \mu \mathrm{m})$ of the GC-MS. Alditol acetates of authentic standards (glucose, mannose, rhamnose, galactose, xylose and arabinose) with myo-inositol as the internal standards were prepared and subjected to GC-MS analysis separately in the same way. The operation was performed in the following conditions: injection temperature: $240{ }^{\circ} \mathrm{C}$; detector temperature: $240{ }^{\circ} \mathrm{C}$; column temperature programmed: $160{ }^{\circ} \mathrm{C}$ holding for $2 \mathrm{~min}$, then increasing to $240{ }^{\circ} \mathrm{C}$ at $5{ }^{\circ} \mathrm{C} / \mathrm{min}$ and finally holding for $5 \mathrm{~min}$ at $240{ }^{\circ} \mathrm{C}$. Nitrogen was used as the carrier gas and maintained at $1.0 \mathrm{~mL} / \mathrm{min}$.

\subsection{Infrared Spectra of DFHP}

The structural characteristics of the DFHP were determined by Fourier transform IR spectrophotometer (Perkin-Elmer Corp., USA). The purified polysaccharide DFHP was ground with $\mathrm{KBr}$ powder and then pressed into pellets for transform IR spectral measurement in the frequency rang of $4000-500 \mathrm{~cm}^{-1}$ [26].

\subsection{NMR Identification}

Twenty milligrams of DFHP was dissolved in $\mathrm{D}_{2} \mathrm{O}(0.5 \mathrm{~mL}, 99.9 \%)$, freeze-dried, and redissolved in $\mathrm{D}_{2} \mathrm{O}(0.5 \mathrm{~mL})$. The ${ }^{1} \mathrm{H}-\mathrm{NMR}$ and ${ }^{13} \mathrm{C}-\mathrm{NMR}$ spectra were measured in an NMR tube (5 mm diameter) at $27{ }^{\circ} \mathrm{C}$ with a Bruker Avance 600 spectrometer. The chemical shift was expressed in parts per million (ppm).

\subsection{Assays for Antioxidant Activities}

\subsubsection{DPPH Radicals Scavenging Assay}

In the present test, DPPH scavenging activities of the DFHP was measured according to the method of Shimada et al. [27] and Wei et al. [28], with some modifications. Vitamin C was used as reference material. Briefly, $0.1 \mathrm{mM}$ solution of DPPH in methanol was prepared and $1.0 \mathrm{~mL}$ of this solution was added with $3.0 \mathrm{~mL}$ of the samples of various concentrations $(0.001-3.000 \mathrm{mg} / \mathrm{mL})$. The solution was kept at room temperature for $30 \mathrm{~min}$, and the absorbance at $517 \mathrm{~nm}\left(\mathrm{~A}_{517}\right)$ was measured. The DPPH scavenging effect was calculated as follows:

DPPH scavenging effect $(\%)=[\mathrm{Ao}-(\mathrm{A}-\mathrm{Ab})] / \mathrm{Ao} \times 100$

Where Ao: $A_{517}$ of DPPH without sample, A: $A_{517}$ of sample and DPPH, and Ab: $A_{517}$ of sample without DPPH. 


\subsubsection{Hydroxyl Radical Scavenging Assay}

The hydroxyl radicals scavenging activity of the polysaccharide was measured according to the method of Wang et al. [29], with some modifications. Different concentrations $(0.001-3.000 \mathrm{mg} / \mathrm{mL})$ samples were incubated with $2.0 \mathrm{mmol} / \mathrm{L}$ EDTA-Fe $(0.5 \mathrm{~mL}), 3 \% \mathrm{H}_{2} \mathrm{O}_{2}(1.0 \mathrm{~mL})$ and $0.36 \mathrm{mg} / \mathrm{mL}$ crocus in $4.5 \mathrm{~mL}$ sodium phosphate buffer $(150 \mathrm{mM}, \mathrm{pH} 7.4)$ for $30 \mathrm{~min}$ at $37{ }^{\circ} \mathrm{C}$ and hydroxyl radical was detected by monitoring absorbance at $520 \mathrm{~nm}$. The hydroxyl radical scavenging effect was calculated as follows:

Hydroxyl radical scavenging effect $(\%)=[(\mathrm{Ac}-\mathrm{As}) / \mathrm{Ac}] \times 100$

Where $A s$ is the $A_{520}$ of sample and $A c$ is the $A_{520}$ of control, in the control, sample was substituted with distilled water, and sodium phosphate buffer replaced $\mathrm{H}_{2} \mathrm{O}_{2}$.

\subsubsection{ABTS Radicals Scavenging Assay}

The radicals scavenging activity of DFHP against radical cation $\left(\mathrm{ABTS}^{+}\right)$was measured using the methods of Re et al. [30] and Luo et al. [31], with some modifications. $\mathrm{ABTS}^{+}$was produced by reacting $7 \mathrm{mmol} / \mathrm{L}$ of $\mathrm{ABTS}^{+}$solution with $2.45 \mathrm{mmol} / \mathrm{L}$ of potassium persulphate, and the mixture would be kept in the dark at room temperature for $16 \mathrm{~h}$. In the moment of use, the $\mathrm{ABTS}^{+}$solution was diluted with ethanol to an absorbance of $0.70 \pm 0.02$ at $734 \mathrm{~nm}$. The sample $(0.2 \mathrm{~mL})$ with various concentrations $(0.001-3.000 \mathrm{mg} / \mathrm{mL})$ were added to $2 \mathrm{~mL}$ of $\mathrm{ABTS}^{+}$solution and mixed vigorously. After reaction at room temperature for $6 \mathrm{~min}$, the absorbance at $734 \mathrm{~nm}$ was measured. The $\mathrm{ABTS}^{+}$ scavenging effect was calculated by the following formula:

ABTS scavenging effect $(\%)=[\mathrm{Ao}-(\mathrm{A}-\mathrm{Ab})] / \mathrm{Ao} \times 100$

Where Ao: $\mathrm{A}_{734}$ of ABTS without sample, A: $\mathrm{A}_{734}$ of sample and ABTS, and Ab: $\mathrm{A}_{734}$ of sample without ABTS.

\subsection{Statistical Analysis}

The data were presented as mean \pm standard deviation. Statistical analysis was conducted with the SPSS 16.0 software package.

\section{Conclusions}

In the present study, the polysaccharide DFHP(Mw $209.3 \mathrm{kDa})$ was first isolated from the stem of Dendrobium fimhriatum Hook.var.oculatum Hook. with the dominance of mannose, glucose, galactose. Free radicals scavenging activities in vitro indicated that DFHP has significant radicals scavenging abilities on ABTS and Hydroxyl radicals. The scavenging effects were powerful, and close to the positive control $(\mathrm{Vc})$. Therefore, the polysaccharide DFHP should be explored as novel potential antioxidants. On the other hand, DFHP exhibited a weak scavenging effect on DPPH radical compared to the reference. Therefore, further investigation of its antioxidant activities in vivo would elucidate this further, and the detection of the mechanism of action relevant to its anti-oxidative activity will be carried out in future studies. 


\section{Acknowledgments}

This study was supported by the Education Department Foundation of Sichuan Province of China (08ZA074).

\section{References}

1. Majumder, P.L.; Guha, S.; Sen, S. Bibenzyl derivatives from the orchid Dendrobium amoenum. Phytochemistry 1999, 52, 1365-1369.

2. Yang, L.; Qin, L.H.; Annie Bligh, S.W.; Bashall, A.; Zhang, C.F.; Zhang, M.; Wang, Z.T.; $\mathrm{Xu}$, L.S. A new phenanthrene with a spirolactone from Dendrobium chrysanthum and its anti-inflammatory activities. Bioorg. Med. Chem. 2006, 14, 3496-3501.

3. Wang, Q.; Gong, Q.; Wu, Q.; Shi, J. Neuroprotective effects of Dendrobium alkaloids on rat cortical neurons injured by oxygen-glucose deprivation and reperfusion. Phytomedicin 2010, 17, 108-115.

4. Fan, Y.J.; Luo, A.X.; Luo A.S.; Chun Z. Research on the ultrasonic-assisted extraction process for polysaccharide from D.denneanum. Chin. J. Hosp. Pharm. 2009, 22.1909-1911.

5. Fan, Y.J.; Luo, A.X. Evaluation of anti-tumor activity of water-soluble polysaccharides from Dendrobium denneanum. Afr. J. Pharm. Pharmaco. 2011, 5, 415-420.

6. Zha, X.Q.; Luo, J.P.; Luo, S.Z.; Jiang, S.T. Structure identification of a new immunostimulating polysaccharide from the stems of Dendrobium huoshanense. Carbohyd. Polym. 2007, 69, 86-93.

7. Wang, J.H.; Luo, J.P.; Zha, X.Q.; Feng, B.J. Comparison of antitumor activities of different polysaccharide fractions from the stems of Dendrobium nobile Lindl. Carbohyd. Polym. 2010, 79, 114-118.

8. Luo, A.X.; Ge, Z.F.; Fan, Y.J.; Luo, A.S.; Chun, Z.; He, X.J. In vitro and in vivo antioxidant activity of a water-soluble polysaccharide from dendrobium denneanum. Molecules 2011, 16, 1579-1592.

9. Zhao, Y.P.; Son, Y.O.; Kim, S.S.; Jang, Y.S.; Lee, J.C. Antioxidant and anti-hyperglycemic activity of polysaccharide isolated from dendrobium chrysotoxum lindl. J. Biochem. Mol. Biol. 2007, 40, 670-677.

10. Fan, Y.J.; He, X.J.; Zhou, S.D.; Luo, A.X.; He, T.; Chun, Z. Composition analysis and antioxidant activity of polysaccharide from Dendrobium denneanum. Int. J. Biol. Macromol. 2009, 45, 169-173.

11. Santhiya, D.; Subramanian, S.; Natarajan, K.A. Surface chemical studies on sphalerite and galena using extracellular polysaccharides isolated from bacillus polymyxa. J. Colloid Interf. Sci. 2002, 256, 237-248.

12. Park, F.S. Application of I.R. Spectroscopy in Biochemistry, Biology, and Medicine; Plenum Press: New York, NY, USA, 1971; pp. 100-140.

13. Zhao, M.M.; Yang, N.; Yang, B. Structural characterization of water-soluble olysaccharides from Opuntia monacanthap cladodes in relation to their anti-glycated activities. Food Chem. 2007, 105, 1480-1486. 
14. Barker, S.A.; Bourne, E.J.; Stacey, M.; Whiffen, D.H. Infrared spectra of carbohydrates. Part I. Some derivatives of D-glucopyranose. J. Chem. Soc. 1954, 99, 171-176.

15. Maiti, D.; Chandra, K.; Mondal, S.; Ojha, A.K.; Das, D.; Roy, S.K.; Ghosh, K.; Chakraborty, I.; Islam, S.S. Isolation and characterization of a heteroglycan from the fruits of Astraeus hygrometricus. Carbohyd. Res. 2008, 343, 817-824.

16. Roy, S.K.; Maiti, D.; Mondal, S.; Das, D.; Islam, S.S. Structural analysis of a polysaccharide isolated from the aqueous extract of an edible mushroom, Pleurotus sajor-caju, cultivar Black Japan. Carbohyd. Res. 2008, 343, 1108-1113.

17. Cao, W.; Li, X.Q.; Liu, L.; Yang, T.H.; Li, C.; Fan, H.T.; Jia, M.; Lv, Z.G.; Mei, Q.B. Structure of an anti-tumor polysaccharide from Angelica sinensis (Oliv.) Diels. Carbohyd. Polym. 2006, 66, $149-159$.

18. He, Y.M.; Liu, C.H.; Chen, Y.X.; Ji, A.C.; Shen, Z.L.; Xi, T.; Yao, Q.S. Isolation and structural characterization of a novel polysaccharide prepared from Arca subcrenata Lischke. J. Biosci. Bioeng. 2007, 104, 111-116.

19. Yoon, S.; Kim, M.K.; Lee, I.Y.; Yun, M.; Nam Shin, J.E. Production and structural features of a water-soluble polysaccharide from a mutant strain of Agrobacterium sp. J. Ind. Eng. Chem. 2008, $14,759-764$.

20. Kath, F.; Kulicke, W.M. Mild enzymatic isolation of mannan and glucan from yeast Saccharomyces cerevisiae. Angew. Makromol. Chem. 1999, 268, 59-68.

21. Han, J.; Weng, X.C.; Bi, K.S. Antioxidants from a Chinese medicinal herb-Litho-spermum erythrorhizon. Food Chem. 2008, 106, 2-10.

22. Luo, A.X.; He, X.J.; Zhou, S.D.; Fan,Y.J.; He, T.; Chun, Z. In vitro antioxidant activities of a water-soluble polysaccharide derived from Dendrobium nobile Lindl. Extracts. Int. J. Biol. Macromol. 2009, 45, 359-363.

23. Navarini, L.; Gilli, R.; Gombac, V.; Abatangelo, A.; Bosco, M.; Toffanin R. Polysaccharides from hot water extracts of roasted Coffea arabica beans: Isolation and characterization. Carbohyd. Polym. 1999, 40, 71-81.

24. Yamamoto, Y.; Nunome, T.; Yamauchi, R.; Kato, K.; Sone, Y. Structure of an exocellular polysaccharide of Lactobacillus helveticus $\mathrm{TN}-4$, a spontaneous mutant strain of Lactobacillus helveticus TY1-2. Carbohyd. Res. 1995, 275, 319-332.

25. Pang, X.B.; Yao, W.B.; Yang, X.B.; Xie, C.; Liu, D.; Zhang, J.; Gao, X.D. Purification, characterization and biological activity on hepatocytes of a polysaccharide from Flammulina velutipes mycelium. Carbohyd. Res. 2007, 70, 291-297.

26. Luo, A.X.; He, X.J.; Zhou, S.D.; Fan, Y.J.; Luo, A.S.; Chun, Z. Purification, composition analysis and antioxidant activity of the polysaccharides from Dendrobium nobile Lindl. Carbohyd. Polym. 2010, 79, 1014-1019.

27. Shimada, K.; Fujikawa, K.; Yahara, K.; Nakamura, T. Antioxidative properties of xanthan on the autoxidation of soybean oil in cyclodextrin emulsion. J. Agr. Food Chem. 1992, 40, 945-948.

28. Wei, S.D.; Zhou, H.C.; Lin, Y.M. Antioxidant activities of extract and fractions from the hypocotyls of the Mangrove Plant Kandelia candel. Int. J. Mol. Sci. 2010, 11, 4080-4093.

29. Wang, J.; Zhang, Q.B.; Zhang, Z.S.; Li, Z. Antioxidant activity of sulfated polysaccharide fractions extracted from Laminaria japonica. Int. J. Biol. Macromol. 2008, 42, 127-132. 
30. Re, R.; Pellegrini, N.; Proteggente, A.; Pannala, A.; Yang, M.; Rice-Evans, C. Antioxidant activity applying an improved ABTS radical cation decolorization assay. Free Rad. Bio. Med. 1999, 26, 1231-1237.

31. Luo, A.X.; Fan, Y.J.; Luo, A.S. In vitro free radicals scavenging activities of polysaccharide from polygonum multiflorum thunb. J. Med. Plants Res. 2011, 5, 966-972.

(C) 2011 by the authors; licensee MDPI, Basel, Switzerland. This article is an open access article distributed under the terms and conditions of the Creative Commons Attribution license (http://creativecommons.org/licenses/by/3.0/). 